\title{
Gender Differences in the Use of a Public Library
}

\author{
Rachel Applegate
}

\begin{abstract}
Experience and anecdotal evidence suggest that men and women use-or do not use-public libraries in different ways and amounts. Compared to extensive research on male and female differences in reading, computer use or within the context of the school library, there is relatively little descriptive research showing the library preferences of adult men and women. This study analyzed over 1,200 user responses in a survey conducted as part of a strategic planning process of an affluent public library. Male patrons in many respects were simply below-average in many areas (fewer visits, fewer services or resources used) but also showed distinctly different choices in a few areas, mainly related to electronic and business-related items. They also are almost completely uninterested in children's areas, a sharp contrast with adult female patrons). Male usage is distinct enough to warrant special attention from library planners. The results help library managers understand better what different patrons already use, and those areas where greater marketing or different strategic choices may be needed.
\end{abstract}

In a 2001 essay in Library Journal, Marylaine Block ${ }^{1}$ argued for a greater focus on maleoriented magazines and books. Block presented no data on male preferences within the library context, an area for which there is comparatively little information.

Several major studies of library users, or of that notoriously difficult subject, the general public including non-library users, do not report gender differences. These include the 1994 study by D'Elia and Rodger ${ }^{2}$ on the roles of the public library, the Walzer, Scott, and Sutton 2000 and 2001 study of Illinois residents ${ }^{3}$ and the Metropolitan Cooperative Library System's 1999 study of California residents. ${ }^{4}$

The comprehensive and in many ways ground-breaking OCLC study ${ }^{5}$ of the general public in several countries (but conducted online, therefore reaching only a self-selected subset of the population as a whole), breaks down its respondents into categories of card holders, college students, age groups, and country. Gender differences are not reported.

In a "smartsearch" of the term "gender" in Library Literature, of the 36 items retrieved, almost half (16 items or 44\%) concerned differences between the genders in children. Six addressed gender differences in management and five in scholarship or publication. The remaining eight were on a wide variety of topics, with three concerned with some computer or Internet issues (web advertising, Internet commerce, and the Internet in general), two were casual columns, and three covered oral communication of technical information, science fiction collections and the history of literacy. 
Only one out of the 36 joined library collections to a more-adult population, a study of Malaysian undergraduates' use of e-books. ${ }^{6}$ In this study, men were more likely to be interested in and to frequently use e-books. Although the author of the study did not analyze this statistic, the male edge may be associated with another study finding: that the most common subject of ebooks used was the field of computers and information technology. Assuming that Malaysian undergraduates studying those fields are at least as male-dominated as in the United States, the greater use of e-books by men may simply be a function of greater availability of titles in the area of their major studies.

In 1977 Zweizig and Dervin, in their review of public library user studies, ${ }^{7}$ argued that studies of who used the library and how much had been "pushed as far as is helpful” (p.252). However, the library itself has changed and is changing. Many of the changes involve issues that appear to have gender dimensions (such as the notorious but fast-changing digital gender divide (see, for example, Ching, Bashan and Jang's 2005 study $^{8}$ ), and, therefore. it is valuable to keep monitoring, to see if certain functions of the library are no longer valued, or if certain people no longer value the library.

\section{Methodology}

The present study analyzes data from 1,073 respondents to a paper, in-person survey handed out to visitors to a suburban public library during one week in September 2005. Surveys were passed out by both male and female staffers and volunteers, and nearly all adults approached cooperated in the survey. Since the average patron reported visiting the library once every three weeks, it is probable that this survey reached $20-30 \%$ of the system's current library users.

This distribution methodology represents a 'snapshot' rather than a random representative sampling of the library users as a whole, and certainly does not include non-library users. The more infrequent the library use, in fact, the less likely a person was to be a respondent. However, male respondents were actually slightly more likely than women to report more-frequent library use.

The host library was Carmel Clay Public Library (CCPL), a main-only (no branches) library located in an affluent suburb north of Indianapolis, Indiana (Table 1). Median household income for the city of Carmel was \$81,583 in 2000 (U.S. Census).

CCPL compares very favorably to other libraries in the country, ranking highly in the Hennen library rankings, which focus on circulations, attendance and other measures of activity, considered on a per-capita basis (third among libraries serving populations of 50,000-100,000). ${ }^{9}$

These two features of this library - its comparatively generous resources, and its singleness (no branches) - are beneficial for this analysis. No difference needs to be accounted for between branch and main library users or facilities, collections, and services. Further, the library is able to offer a very broad range of well-established services and collections. Patrons are less likely to not use or value library features because of a lack of quality (which might happen in an underfunded library), but are more likely to make choices based on preferences, not availability. 
The survey had three parts. In the first, respondents identified themselves in age ranges, by gender, and by general place of residence within the service area. In the second, several questions asked about their use of the library in general (frequency, whether it had changed, and how well informed about the library they believed they were). In the final section, a list of 45 items was presented. For each, respondents checked whether they were "aware of" it, "used" it, or thought it "very important." The items included facility features (e.g., copy machines or coffee shop), services (e.g. interlibrary loan, reference, readers' advisory), materials (e.g. non-fiction, children's), and "e" items such as placing holds online or receiving email notification of due dates.

The items on the survey represent those offered at this one specific library, because of the local evaluative rationale for the original survey. The items are somewhat more comprehensive than in other studies: Stephens, for example, omitted asking whether libraries offered collections of fiction or of magazines, because those were considered to be universal. ${ }^{10}$ Compared to the "roles" listed in the Public Library Association's major planning guide (The New Planning for Results), ${ }^{11}$ the majority of which are concerned with 'information' of various sorts, the survey items include far more choices related to personal, leisure or recreational activities.

After the survey was complete, the author received permission from the human subject research committee of her institution (the Indiana University-Purdue University Indianapolis Institutional Review Board) to analyze the data under the 'exempt' category of existing data. No individually identifiable information was collected or preserved.

\section{Results: Male and Female Preferences in Library Use and Preferences}

There were a total of 1,083 (93\%) of all respondents with valid gender identification. Of those, $68 \%$ were female and $32 \%$ male. For men, there was a relatively straight participation trend line by age: the older the age group, the more male patrons (Fig. 1).

Women library users were most likely to be in their middle years: 25 to 49 . Just over $40 \%$ of all library users were women between 25 and 49.

Women tended to report that they used more items-about one and a half items per woman compared to one item for men. The difference is small but statistically significant: $12.3 \mathrm{vs.10.8}$ for men. Women also tended to identify a few more (1.3 on average) items as "very important": 8.2 vs. 6.9 (also statistically significant).

Male respondents differed significantly in their frequency of library use, although perhaps in a surprising direction. A greater percentage of men than women reported visiting the library more than once per week; fewer reported visiting every two weeks; in other categories, their percentages were essentially the same (Fig. 2). Moreover, fewer men reported that their use of the library had changed: only $32 \%$ of men vs. $43 \%$ of women. Probably in order to encourage honesty (avoiding people not wanting to admit to a decrease), the survey just asked, "changed," 
without specifying an increase or decrease. The results however, are similar to the 33\% of respondents noting that their library use had decreased in a 1994 study $^{12}$ (D'Elia and Rodger).

Analyzing the entire range of forty-five possibilities (Table 2), it would be easy to get swamped in minute variations. Furthermore, because of the large number of responses, items considered individually quite often showed statistically significant differences between men and women patrons-but most of the time the relationship, for an individual item, was relatively weak. In the survey as a whole, there were only seven items - table 3 which had a correlation (strength of relationship) between gender and use of greater than .10 .

The two top items more often used by men were 'e' services. This finding will be seen in the next analysis, which examines larger patterns and groupings of library usage.

To move beyond these specific items - to see some forests rather than individual trees-another approach is to explore larger patterns in male and female use of library resources, services, and programming.

One way to detect patterns in survey respondents is with "factor'” or "cluster" analysis. With this method, a statistical program looks for items which cross-correlate, to see if there are clusters of items which all seem to be related to one another. For example, someone who likes Motor Trends may also like Car and Driver and Hot Rod. Applying a simple mathematical approach to factor analysis here was not useful, however, as one large "factor" of more than 30 items was identified.

A second approach was taken. Seven 'indexes' were created from selected items, using content/face validity: that is, items deliberately selected as 'meaning' the same thing in a library setting. The extent to which this grouping works - the extent to which it reflects some real relationship among the items, is measured by a reliability score (Cronbach's alpha).Table 4 gives the reliability scores of these seven indexes.

Generally, an alpha score over .70 is considered reliable for group description (over .90 is desired in order to describe or score individuals). Electronic resources, print materials, and general services are discussed in more detail due to their low scores, which indicates a greater internal variability.

Table 5 gives the average usage figure for each index for men and women survey respondents. The indexes have been adjusted to fit a 0-10 range. That is, if each scale represented 10 items, the number given would be the average number of items used by the respondents. Each index is made up of from 3 to 6 items (described in detail below).

The only area where male patrons were more likely to report that they used items was in electronic resources. Out of a total of five possible items, the average number of items used for men was 1.19 vs. 0.97 for women. (difference, $\mathrm{p}<.01$ ). This index consists of online databases, online magazines and newspapers, and e-books. 
Electronic services were quite popular with both men and women, and more so with women. These are items which provide more convenience in using library materials: e-mail reminders of due dates, e-mail notification of holds, placing holds online, and use of website. These probably reflect women's greater use of library materials generally-and reinforce the importance of library materials generally for all survey respondents.

The really notable, and the largest, difference is in use of children's items: here, it includes children's print, children's audiovisual, young adult print, and young adult and children's programming. Male patrons are much less likely to report that they use children's or young adult services or materials $(\mathrm{p}<.001)$. They are even less likely to describe them as 'very important': an average of .95 vs. 1.83 for women ( $<<.001$, on the same $0-10$ scale). Remember that the survey only asked the respondent to check a box labeled, "use.” It did not distinguish between personal or second-hand usage.

The child-woman relationship appears important in another area of the survey. When asked "why" their use of the library had changed, the only reason provided for which there was a statistically significant gender difference was "Children have grown" (31 women, 5 men reporting that; $4 \%$ of all women respondents, $1 \%$ of men).

The proportion of all patrons who report use of children's or young adult items is consistently lower for men than for women, but interestingly, use of children's items peaks for men at a later age than for women. For women, use of at least one child or youth item peaks at age 25-39 at $63 \%$ of respondents; for men, at age $40-49$, at $60 \%$ of respondents. The largest gap between men and women is in the $18-24$ year old bracket, where $43 \%$ of women, and only $22 \%$ of men, report using at least one children's or young adult material or service.

Materials are consistently more popular with all respondents than either services or programming. Men and women did not differ in their frequency of reporting use of audiovisual materials (DVDs, videos, CDs, and audio books) (difference $\mathrm{p}>.05$ ). This index had high reliability: people interested in one type of audiovisual material were generally interested in all types.

However, men were less likely to have used print materials: adult non-fiction, fiction, and magazines. Because the reliability figure for this combined index is a relatively low .61, the details are more important. Breaking it down into the individual items, the difference appears in non-fiction and in fiction, but not in magazine usage. For magazines, $22 \%$ of both male and female respondents reported using them. Both non-fiction and fiction were more popular with women: only 45 and $46 \%$ of men reported using either, vs. 59\% of women for fiction and $56 \%$ of women for non-fiction.

Programming and general services each were relatively seldom used, with no significantly differences between men and women. The programming group included book discussion groups, Internet classes, programs for adults (vs. children), and audiovisual programs (film nights). The reliability of this index was relatively high (.73), indicating that those interested in one of this group were generally interested in the others-but few, in any case. 
General services included interlibrary loan, reference, business resources, and reader's advisory. This had a relatively low index reliability score. Examined on an individual basis, two services had no difference between men and women: reference and interlibrary loan. It was in the other two items that there were significant differences - and they were in the opposite direction. Men were more likely to use business resources $(\mathrm{p}<.01)$, both in percentages and in absolute numbers: 47 of 347 respondents (13\%) vs. 40 of 736 (5\%) for women. Women conversely used readers' advisory more than men: 86 out of 736 (12\%) vs. 21 out of 347 for men (6\%).

\section{Discussion}

Many of the findings of this survey will not surprise the observant public library director. More patrons are women, and women seem to make use of a wider variety of library resources and services.

Materials mean a lot to these library patrons. The OCLC perceptions study, which formulated many of its questions around "information" rather than recreational reading, concluded that "Books" are the library "brand." In this study, audiovisual categories were the most used items, but clearly print materials, fiction and non-fiction, were very important, and all materials were more used than services.

The strongest differences between men and women appeared in the use of children's and youth collections and services. Men patrons were relatively less likely to say they used these or that they were important. Men who did report using these areas were on the whole likely to be ten years older than the women users.

It appears from this data that an emphasis on children's and youth services and collections wellserves a large segment of the patron population: women. These women also value collections for adults, and those electronic services which help them make the most convenient use of them.

There are some differences related to electronic items - resources and services. Men more often used wireless access and more often used electronic resources. This may be worth following up on. Again, much research on gender and computer or Internet use seems to be centered on school-age children. Another 'gap' in computer access is income-related; in that regard this difference, found in a community with high average income and high average education levels, is interesting.

Male patrons appear to have some specialized interests, rather than simply being thought of as "like women patrons only less"-less frequent use, less use of various services. For the surveyed library, men appeared to value the business-oriented collection, as well as perhaps the workrelated feature of wireless/laptop access. From this data, it seems doubtful that increasing any activity for children or youth will carry over in increased usage by male patrons. These findings suggest that male use may be increased by deliberately targeting adult male interests for programs and, in particular, business or other specialized collections. 


\section{Tables and Figures}

Table 1

Table 1. Study Setting

\begin{tabular}{lccr}
\hline Library Characteristics & CCPL & Comparison Group Average & National Average \\
\hline Total Revenue Per Capita & $\$ 68.11$ & $\$ 31.90$ & $\$ 33.40$ \\
Collection Expenditures per Capita & $\$ 10.84$ & $\$ 3.94$ & $\$ 4.72$ \\
Circulations per capita & 26.38 & 7.22 & 8.30 \\
Library visits per capita & 11.06 & 4.78 & 5.77 \\
Print materials per capita & 4.35 & 2.70 & 6.50 \\
Audio materials per 1000 & 437.25 & 130.07 & 196.57 \\
ALA MLS Librarians Per Capita & 0.38 & 0.11 & 0.08 \\
\hline
\end{tabular}

Note: Comparison group is U.S. libraries within $\pm 20 \%$ of the CCPL service area population: 64,709

Source: NCES Library Statisttcs Program, Compare Public Libraries http://nces.ed.gov/surveys/libraries/compare/index.asp?LibraryType = Public

Table 2

Table 2. Most-Used Items: Percent of Women or Percent of Men Using the Item

\begin{tabular}{|c|c|c|c|}
\hline Item & $\begin{array}{c}\text { Percent of } \\
\text { Women }\end{array}$ & Item & Percent of Men \\
\hline Email reminder of item due dates & 61 & DVDs, checking out & 58 \\
\hline DVDs, checking out & 60 & CDs, checking out & 52 \\
\hline Adult fiction, checking out & 59 & Email reminder of item due dates & 48 \\
\hline Adult nonfiction, checking out & 56 & Videos, checking out & 46 \\
\hline Placing holds and renewing online & 54 & Adult nonfiction, checking out & 46 \\
\hline Videos, checking out & 51 & Adult fiction, checking out & 45 \\
\hline CDs, checking out & 51 & Placing holds and renewing online & 45 \\
\hline Email notification of holds for pickup & 49 & Library web site & 41 \\
\hline Children's print, checking out & 44 & Computers/Internet & 39 \\
\hline Audiobooks, checking out & 43 & Audiobooks, checking out & 38 \\
\hline
\end{tabular}


Table 3

Table 3. Items Differing Strongly in Usage: Men vs. Women

\begin{tabular}{|c|c|c|c|c|}
\hline & \multirow{2}{*}{$\Delta$} & \multicolumn{2}{|c|}{ Use as $\%$ of respondents of that gender } & \multirow[t]{2}{*}{ Difference } \\
\hline & & Men & Women & \\
\hline Wireless access/laptop hookups & & $24 \%$ & $13 \%$ & $12 \%$ \\
\hline E-mail reminder dates due & & $48 \%$ & $39 \%$ & $9 \%$ \\
\hline Business resources & & $14 \%$ & $5 \%$ & $8 \%$ \\
\hline Book store & & $22 \%$ & $32 \%$ & $-10 \%$ \\
\hline Coffee shop & & $25 \%$ & $36 \%$ & $-11 \%$ \\
\hline Adult fiction check out & & $45 \%$ & $59 \%$ & $-14 \%$ \\
\hline Young adult print check out & & $17 \%$ & $35 \%$ & $-17 \%$ \\
\hline Children's print check out & & $25 \%$ & $44 \%$ & $-19 \%$ \\
\hline
\end{tabular}

Table 4

Table 4. Use Indexes and Reliability Scores

Cronbach's alpha

\begin{tabular}{ll}
\hline Index & Cronbach's á \\
\hline
\end{tabular}

Greater consistency among items:

$\begin{array}{ll}\text { Electronic services } & .82\end{array}$

$\begin{array}{ll}\text { Audiovisual items } & .80\end{array}$

$\begin{array}{ll}\text { Children's items } & .74\end{array}$

$\begin{array}{ll}\text { Programming (adult) } & .73\end{array}$

Greater variability among items:

Electronic resources $\quad .64$

Print materials (adults) $\quad .61$

General services $\quad .58$ 
Table 5

Table 5. Average Use Index Scores

\begin{tabular}{lccc}
\hline & Women & Men & \multicolumn{2}{c}{ Difference } \\
\hline Audiovisual items & 5.1 & 4.8 & N.S. \\
Electronic services & 5.1 & 4.2 & 0.9 \\
Print materials (adult) & 4.6 & 3.7 & 0.9 \\
Children's items & 2.6 & 1.5 & 1.1 \\
Electronic resources & 1.9 & 2.4 & -0.5 \\
General services & 1.5 & 1.5 & N.S. \\
Programming (adult) & 0.9 & 0.8 & N.S. \\
\hline $\begin{array}{l}\text { N }=\text { No use; } 10=\text { All items used by all respondents. } \\
\text { N.S. = The difference is not statistically significant: not different than chance }\end{array}$ \\
\hline
\end{tabular}

[This space left blank intentionally] 
Fig. 1 Respondents by Age and Gender

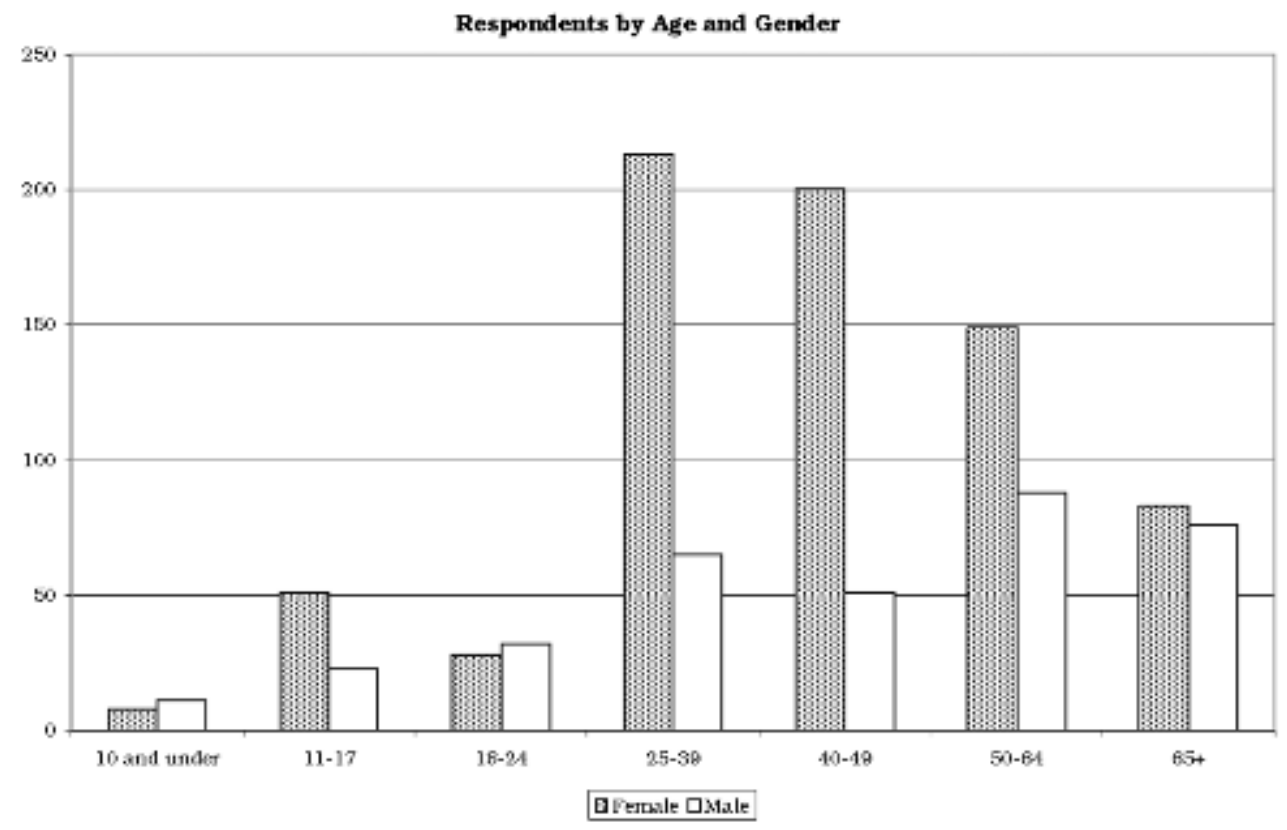

Fig. 2 Frequency of Visits and Percent of Respondents

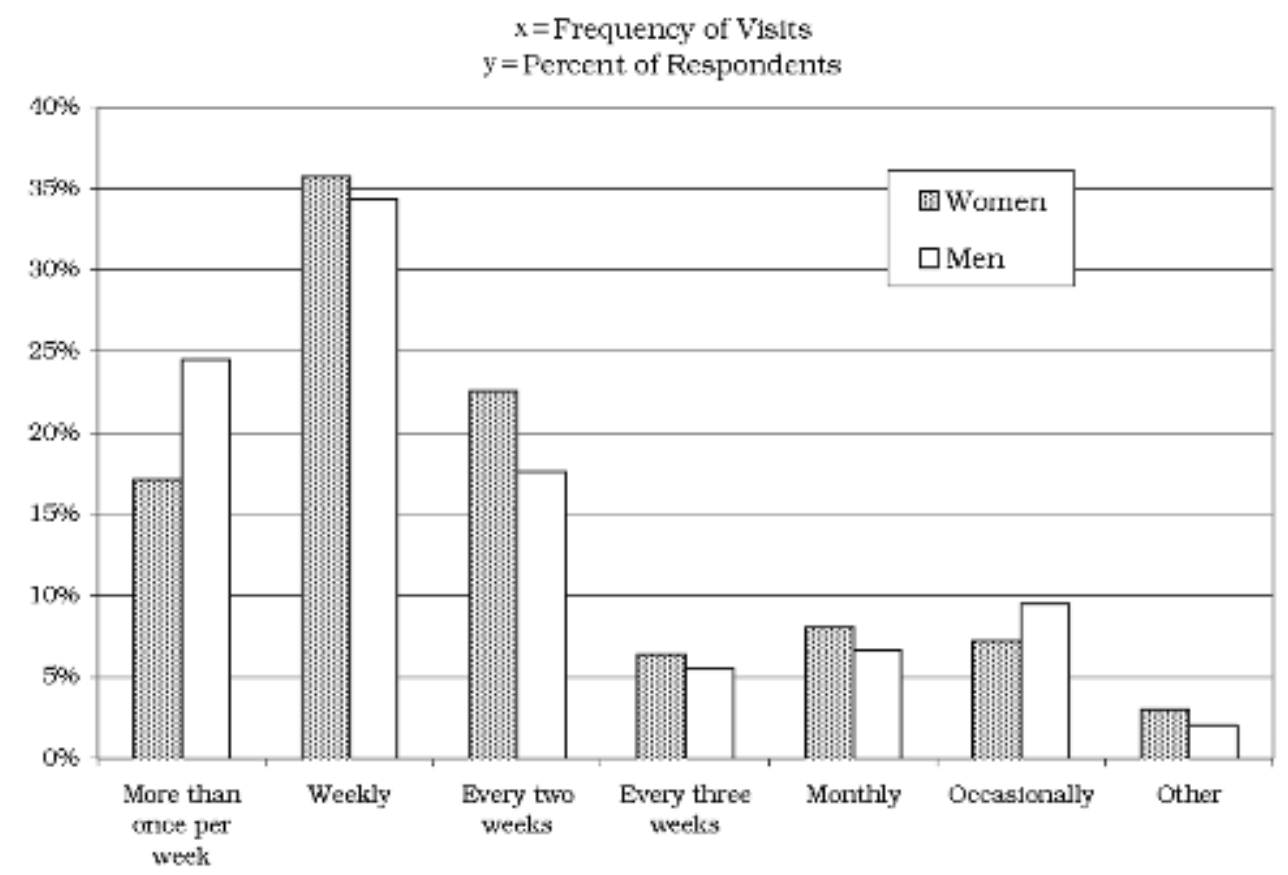




\section{Notes}

1. Marylaine Block. “Serving Men Better.” Library Journal March 1 2001, 60.

2. George D'Elia and Eleanor Jo Rodger, "Public Opinion About the Roles of the Public Library in the Community: The Results of a Recent Gallup Poll.” Public Libraries 33 (1994): 23-28.

3. Norman Walzer, Karen Stott, and Lori Sutton. "The Value of Public Library Service." Illinois Libraries 82, no. 4 (2000): 261-64; Norman Walzer, Karen Stott, and Lori Sutton. "Changes in Public Library Services.” Illinois Libraries 83, no. 1 (2001): 47-52.

4. Metropolitan Cooperative Library System, "Public Perception of Public Libraries: Research Report.” Sacramento: Metropolitan Cooperative Library System, 1999.

5. Cathy De Rosa, Joanne Cantrell, Diane Cellentani, Janet Hawk, Lillie Jenkins, and Alane Wilson. Perceptions of Libraries and Information Resources: A Report to the OCLC Membership. Dublin, OH: OCLC, 2005.

6. Roesnita Ismail and A. N. Zainab, "The Pattern of E-Book Use Amongst Undergraduates in Malaysia: A Case of to Know Is to Use.” Malaysian Journal of Library \& Information Science 10, no. 2 (2005): 1-23.

7. Douglas Zweizig and Brenda Dervin. "Public Library Use, Users, Uses: Advances in Knowledge of the Characteristics and Needs of the Adult Clientele of American Public Libraries." Advances in Librarianship 7 (1977): 231-55.

8. Cynthia Carter Ching, James D. Basham, and Eunice Jang. “The Legacy of the Digital Divide: Gender, Socioeconomic Status, and Early Exposure as Predictors of Full-Spectrum Technology Use among Young Adults.” Urban Education 40, no. 4 (2005): 394-411.

9. Thomas J. Hennen, Jr., “HAPLR Ratings Page.” Hennen's American Public Library Ratings. http://www.haplr-index.com/ratings.html. Retrieved March 15, 2007.

10. Annabel K. Stephens, “Twenty-First Century Public Library Adult Services.” Reference \& User Services Quarterly 45, no. 3 (2006): 223-35.

11. Sandra Nelson and the Public Library Association. The New Planning for Results: A Streamlined Approach. Chicago: American Library Association, 2001.

12. George D'Elia and Eleanor Jo Rodger. "Public Opinion About the Roles of the Public Library in the Community: The Results of a Recent Gallup Poll.” Public Libraries 33 (1994): 23-28. 